\title{
Creating Inclusive Psychological Learning Environments Through Appropriate Learning Assessments and Relevant Curriculum
}

\author{
Luisito M. Nanquil \\ Bulacan State University, Philippines \\ $\square$ Corresponding Author: Luisito M. Nanquil, E-mail: luisito.nanquil@bulsu.edu.ph
}

\section{ARTICLE INFORMATION}

Received: 08 September 2021

Accepted: 02 October 2021

Published: 14 October 2021

DOI: 10.32996/jpbs.2021.1.1.4

\section{KEYWORDS}

Assessment, teaching strategies, inclusion, collaboration, curriculum

\section{ABSTRACT}

This paper presents the researcher's perspectives on the place and value of learning assessment tools that are applicable to the current situation and the traditional settings where students would like to grow and improve. The researcher decided to examine and cover various materials that could identify, explain, and capture the purposes of assessment and the tangible benefits students can get from it. Even the teachers can do self-assessment from the results of the test and through their own conscious and mindful practices. Further, this perspective article covers and explores the roles of relevant curriculum design and appropriate assessments in the teaching and learning environments.

\section{Introduction}

Based on different situations and events in academic settings, the relationship of teaching, assessment, and test is shown clearly. From my own perspective and experience, the core variables or elements are teaching and assessment and testing is only a part of the traditional assessment, as Brown (2004) claimed. In the field of curriculum and instruction, the focus is how a teacher designs and delivers lessons, tasks, and activities but along this is an assessment of learning performance using various tools, procedures, and tasks. Assessment is broader in scope compared to testing. Testing is a method of measuring a student's ability, knowledge, or performance in a given domain (Brown, 2004). It is also an instrument designed for a long time and has been pilot tested for validity and trustworthiness. Testing is similar to the quantitative method in which specific parameters and scopes are being observed to measure and determine a particular variable and/or performance.

Being a seasoned teacher, I seldom administer formal and standardized tests. For me, testing only covers a certain aspect of the learner. It has a limited scope, even if the type of test is multiple choice. The big question is "Does failing a test mean a student is not capable? Definitely not. This view is also backed by Gardener's Theory of Multiple Intelligences which goes, "No test can accurately determine the nature or quality of a person's intelligence. As Gardner has repeatedly pointed out, standardized tests measure only a small part of the total spectrum of abilities. The best way to assess your own multiple intelligences, therefore, is through a realistic appraisal of your performance in the many kinds of tasks, activities, and experiences associated with each intelligence" (Armstrong, 2018).

Communicative competence or communicative language teaching has been widely used in other countries. In this approach, the focus is on developing the fluency of the learner before moving to accuracy. Language and formal testing may not be able to check the whole performance of the student using multiple choice and other types of tests. This is in exception of essays, which may combine different areas and represent the student's writing and critical thinking skills.

A test measures performance, but the results imply the test-taker's ability to use a concept common in linguistics, competence. Most language tests measure one's ability to perform language, that is, to speak, write, read, or listen to a subset of language. In line with this, the importance of a test is shown by intentional requirements such as IELTS, TOEFL, TOIC and the like. A worker who wishes to work in English speaking country is required to hurdle such tests.

As stated earlier, assessment is in a bigger picture compared to testing. Even when language teachers employ instructional strategies and pedagogical tasks, the procedures and outcomes are considered as forms of assessment. For instance, when the

Copyright: (c) 2021 the Author(s). This article is an open access article distributed under the terms and conditions of the Creative Commons Attribution (CC-BY) 4.0 license (https://creativecommons.org/licenses/by/4.0/). Published by Al-Kindi Centre for Research and Development, London, United Kingdom. 
teacher does a whole-class discussion throwing questions about a grammar lesson, he is already trying to appraise or gauge the students' experience, capacity, and performance.

In my years of teaching, I have encountered various types of learners. I usually attempt to identify their needs in the form of needs analysis. Then, from the assessment results, I will conceptualize and design my target objectives, followed by instructional materials development. Even our materials can serve as tools for assessing the performance of the learners.

In the contemporary period where all students and teachers are under the new normal (as they say), more challenges and transitions are seen. The preparation of the test is laborious because of connectivity issues. No matter how stable and strong the internet connection of the teacher is, if the students are having problems with their own connectivity, efforts are wasted and affected. Language assessment should be flexible, adaptive, reflective, and inclusive nowadays in the sense that teachers as much as possible have to find alternative ways and options to reach out to their needs by making their procedures and strategies flexible in manner and nature.

Of course, as language teachers, we can always ponder and decide how we can better assess our students. Through conversation and discussions online, we can always ask them about their struggles and choices which can serve as our basis to refine, retool, and revise our teaching styles and techniques, instructional materials, and assessment tools.

Another point I would like to raise is imposing or implementing performance-based assessment in which, the language teacher can really see how far learner have mastered and incorporated the lessons and ideas by engaging in a task or activity that requires them to speak, read, write, and listen. Furthermore, among other skills (other sources claim imaging and visualizing are macro-skills) critical and analytical thinking is very imperative because all other skills will be null and nil if this area is not working.

What is the ultimate goal of teaching, assessing, and testing our students? Is this dependent on the mandatory requirements of schools? I would say "partly yes" but the main point and rationale of instruction, assessment, and test is to prepare our learners for the bigger world which is the workplace, where they are going to apply what they have learned and gained for the four years of being in collegiate level. I would say that the assessments we give can shape and form the future because of various reasons. If we remember how our elementary schools performed in PISA of Southeast Asia last year, we can infer that our schools are lagging behind when it comes to reading comprehension and numeracy. It is high time that language teachers will consider redefining communication competence based on what the global trends are looking for or requiring. Educators should always consult the Common European Framework of Reference in giving tests and assessments, where the different levels of competencies are enumerated and described. This is also in line with the national roadmap CHED has launched, which will prepare our graduates for the global workplace.

\section{Method}

This perspective paper analyzed and described the insightful and thoughtful reflections of the researcher by providing information and tips on how learning assessments and curriculum planning can help the teachers provide a healthy and inclusive psychological environment for students with diverse backgrounds and needs. The cited materials were very helpful in drawing conclusions and synthesizing key ideas and concepts that could support the researcher's claims. From different perspectives and views, the author attained a bigger picture about assessment and curriculum, which he could share with others to make the learning climate psychologically prepared and conducive.

\section{Literature Review}

Movitz and Holmes (2007) share their experiences teaching high school, where they incorporated learning stations while handling a medieval unit. One key point in their reflection is that learners don't outgrow their love of learning through hands-on and multisensory tasks. They witnessed increased student participation and more meaningful experiences through stations.

On the other hand, Cooperative learning can be an effective mixture together and simply asking students to work together lacks the organization and same goals of effective cooperative learning. Cooperative learning is not just working in groups; rather, it is a purposive, tactical, and structured instructional strategy that promotes a healthy learning environment.

Fielder and Brent (2007) provide logical reasons as to why cooperative learning is attainable and effective. Students can learn better by performing something active rather than simply sitting and listening. They also believe that cooperative learning benefits smarter students, who are put in the position of explaining and summarising concepts to team members who contribute to the team's success.

Macmillan (2021) online course offers insight that says building meaningful relationships and not just transactional. The teacher has to allocate time in each lesson to learn about the lives of his students. The teacher should find out what inspires students and what they feel passionate about. They can also talk about themselves and value communication practice. With the chance 
provided by the teacher to understand his students and understand one another, this situation forges stronger bonds among members of the class-leading to creating a more supportive and inclusive classroom environment.

It also suggests that teachers be transparent by offering full disclosure on why they present the lesson and how tasks and materials are designed to help students achieve progress. Explaining the purpose of the tasks, activities, and approaches to students provide them a roadmap for completion and motivation.

When teachers use multimodality and progressive tasks in classrooms, they provide alternative routes for the learners and create opportunities for them to pick up gold along the way. As expedition leaders, teachers can observe which paths their adventurers (learners) choose and encourage them to reflect on which have been useful. The activities, strategies, approaches that students identify as useful can be compared with gold nuggets picked up on their way. These gold nuggets help students for future learning and help teachers differentiate and cater for students' attitudes, skills, and performances.

Another approach is to provide progressive tasks that slowly increase in difficulty, allowing learners to work at their own pace, and empowering them to work independently. Some students work quickly through tasks. What matters most is that the progress of students from their beginning points, not that they all work the same (Tomlinson, 2017). Some students need extra challenges while others need extra assistance.

\section{Results and Discussion}

From the views and thoughts of the researcher as supported by the literature and sources, there is a need for educators to be flexible and dynamic in choosing and designing the curriculum, syllabus, and instructional assessments for the target learners.

Educators and language specialists are one in saying that instructional materials can help in the transmission of knowledge and concepts. Language teachers cannot confine themselves to lectures and discussions because students get bored and won't participate in a class that appears to them as monotonous and traditional. So we have to break class monotony! The kinds of materials we use in the class can help us get the attention of the learners and motivate them to be engaged in discussions, activities, and tasks. However, in choosing and designing our instructional materials, we have to consider the class's needs, nature and scope of the subject, specific topics and themes, and the culture and ethnicity of the learners. Language teachers should be critical and reflective thinkers who can creatively design their materials.

Students come into the class to be engaged and to enjoy. If they get bored in the class that always uses the lecture method, students feel truant and uninterested. Teachers may teach the same subject and handle the same students but they would certainly differ in terms of strategies. There are different strategies to employ in the language class. These strategies could be differentiated instruction, whole-class discussion, task-based language teaching, content-based instruction, eclectic method, brainstorming session, question-recitation, project-based activity, and communicative language teaching (this is an approach). It is, of course, true that there is no one best method in the class, but there are appropriate methods and strategies suitable for a specific type of learners. The language teacher needs to be flexible, prudent, patient, and reflexive.

\section{Conclusions and Implications}

I have been handling educational research (research design and methodology) in the school where I am connected with. I noticed that despite the fluency and accuracy of learners in English, they are still groping in the darkness when research is the subject. Hence, I decided to assess and identify possible reasons and causes. From my findings, this learning assessment technique will be applied to address the dominant needs and problems. I also realized that I have to explore different materials and references that will connect and fit with the given situation and context where students are in.

The success of any subject and program lies heavily on the kind of curriculum developed by the experts and teachers. At this point, we have to stress that all activities, lessons, and tasks stipulated in the curriculum should be aligned or related to the scope and sequence of the document. Moreover, the learning objectives, rationale, and goals are one in carrying out and translating the vision and mission of the school where the program and curriculum are being offered. Curriculum and instructional design are inseparable, that is, curriculum is the content of everything that is expected to be mastered by the learners and the learning outcomes that should be visible and apparent to the learners as they take up the course until they finish it. Instructional planning involves and includes the methods, strategies, learning plans, approaches, and units with modules that complete the content of the curriculum. In other words, the curriculum is the content, while the instructional design is the form. What is to be taught is the curriculum and how it should be taught and organized is the instructional plan. The focus of all curriculum models is always the learner and the outcomes are the evidence of learning. Knowledge of the curriculum models and theories can direct and guide teachers to develop, design, implement, and evaluate their own curricula in schools. 


\section{References}

[1] Armstrong, T. (2018). Multiple intelligences in the classroom ( $4^{\text {th }}$ edition). Alexandria, USA: ACSD.

[2] Brown, H. Douglas. (2004). Language Assessment: Principles and Classroom Practices. New York: Pearson Education, Inc.

[3] Movitz, A.P. and Holmes, K.P. (2007). Finding center: How learning centers evolved in a secondary, student-centered classroom. English Journal., 96(3), 68-73.

[4] Fielder, R.M., and Brent, R. (2007). Cooperative learning. In P.A. Mabrouk (Ed.), Active learning: Modules from the analytical sciences (pp.3453). Washington, D.C. American Chemical Society.

[5] (2021). www.macmillanenglish.com

[6] Tomlinson, C.A. (2017). How to differentiate instruction in academically diverse classrooms, Alexandria, VA: Association for Supervision and Curriculum Development.

[7] Rollins, S.P. (2017). Teaching in the fast lane: How to create active learning experiences. ASCD. 